${ }^{2}$ Department of Opthalmology, Leeds General Infirmary

Clarendon Wing, Belmont Grove

Leeds LS2 9NS, UK

Correspondence: D Varma

Tel: +44 1912824410

Fax: +44 1912275246

E-mail: deepalivarma@hotmail.com

Sir,

\section{Calcification in Schwannoma of the lacrimal gland region}

Eye (2004) 18, 218-219. doi:10.1038/sj.eye.6700589

Schwannoma is a localized, encapsulated, benign nerve sheath tumour occurring anywhere along the course of a peripheral sympathetic or cranial nerve. It accounts for $1 \%$ of all orbital tumours. ${ }^{1}$ Most orbital schwannomas arise from the branches of either the supraorbital or the supratrochlear nerve. ${ }^{2}$ Cyst formation is characteristic of orbital schwannomas. ${ }^{2,3}$ We report a case of orbital schwannoma in the lacrimal gland region which was characterized by calcification.

\section{Case report}

A 35-year-old male presented with an increase in fullness in the superotemporal quadrant of the right eye of 10 days duration. He had noticed downward displacement of the right eye for the last 12 years. He gave no history of trauma or similar lesion elsewhere. His visual acuity was $6 / 6$ in both eyes. Ocular movement in the right eye was restricted only in up gaze. The patient did not complain of diplopia. Hertels exophthalmometry measured $19 \mathrm{~mm}$ in the right eye and $15 \mathrm{~mm}$ in the left eye. Intraocular pressure was $16 \mathrm{mmHg}$ in both eyes. Anterior and posterior segment examination was unremarkable.

On palpation, the mass was located in the superotemporal quadrant of the right orbit causing an S-shaped deformity of the upper lid. The mass measured $2 \mathrm{~cm}$ horizontally and $1 \mathrm{~cm}$ vertically. The posterior extent could not be palpated. It was firm in consistency, not compressible, and not adherent to the overlying skin. Schirmer test reading was $15 \mathrm{~mm}$ in the right eye and $35 \mathrm{~mm}$ in his left eye.

The computerized tomography (CT) scan showed a well-defined extraconal mass in superolateral quadrant of the right orbit in relation to the lacrimal gland. The mass had heterogeneous density with large chunky coarse calcification within (Figure 1). A working diagnosis of pleomorphic adenoma was made based on CT-scan findings. His preoperative haemogram, blood biochemistry, liver function tests, and urinalysis were
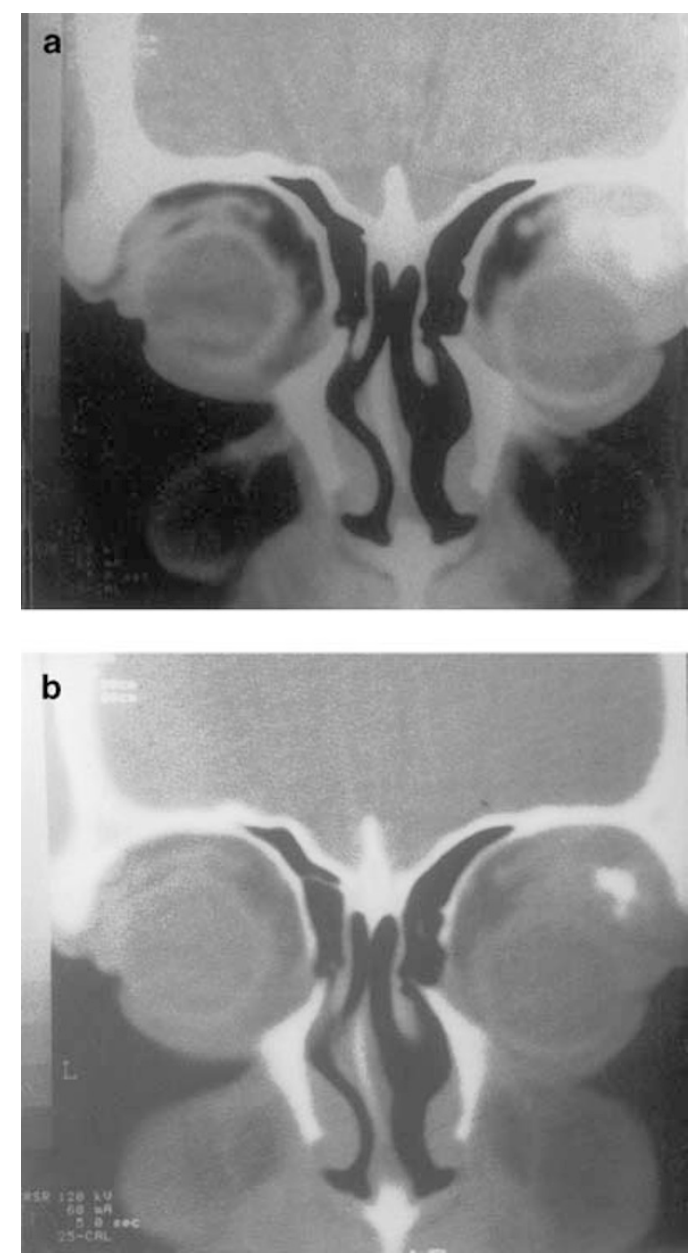

Figure 1 (a) (Noncontrast) Coronal cut of CT scan showing a well-defined mass in the superolateral aspect of the right orbit with a hyperdense speck suggestive of coarse calcification. (b) Contrast enhanced CT scan of the same patient showing minimal enhancement of the lesion with dense enhancement in the centre.

within normal limits. We performed an excision biopsy through a superior orbitotomy and removed an encapsulated mass.

Histopathology: Gross specimen revealed a tumour mass measuring $1.8 \times 1 \times 1.8 \mathrm{~cm}$, greyish white in colour, firm to hard in consistency and had gritty sensation on slicing. Microscopic examination showed a well-defined capsule with characteristic features of palisading of the spindle cells, regimentation, verocay bodies, and a discrete area of calcification (Figure 2). The vessel walls were thickened and hyalinized. The diagnosis of schwannoma was confirmed by immunoperoxidase stain, which was highly positive for S-100 protein.

\section{Comment}

Peripheral nerve sheath tumours of the lacrimal fossa region are very rare. The ciliary nerves are the most 

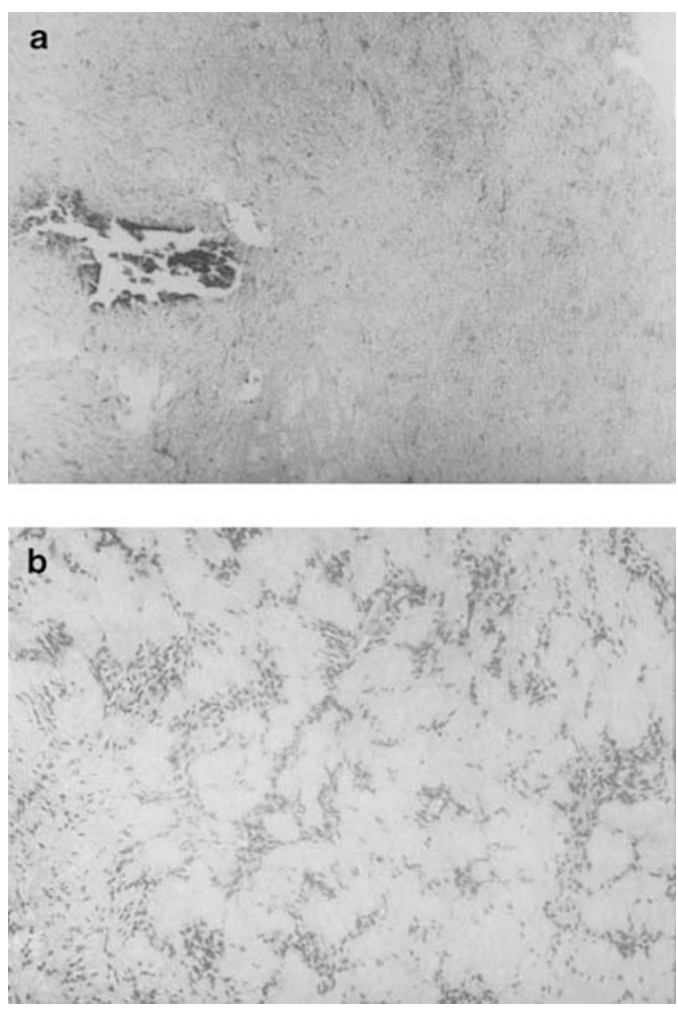

Figure 2 (a) Histopathology of the schwannoma showing an area of calcification surrounded by many spindle cells (haematoxylin and eosin, $\times 44$ ). (b) Magnified view of schwannoma depicting typical pattern of palisading and verocay bodies (Hemotoxylin and eosin, $\times 144$ ).

common nerves of origin of orbital schwannomas. ${ }^{4}$ Till date, there are only two reports of a schwannoma arising from the lacrimal nerve. ${ }^{5,6}$ In this case too, it may have been arising from the lacrimal nerve, as it was located in the lacrimal fossa region although we were unable to confirm it.

Orbital calcification in the lacrimal fossa region is seen in dermoid cyst, dermolipoma, plasmacytoma, and malignant epithelial tumours. Calcification is rarely seen in schwannoma. Rootman $e t \mathrm{al}^{7}$ found calcification in one orbital schwannoma. Although imaging studies such as ultrasonography, CT scan, and magnetic resonance imaging (MRI) are helpful in the diagnosis of schwannoma, there is no single diagnostic feature among these investigations. In most cases, the diagnosis is based on the characteristic histopathology. Owing to the rarity of neurogenic tumours occurring in the lacrimal gland region and presence of calcification within the mass, we did not consider schwannoma in the differential diagnosis. We conclude that schwannomas should be included in the differential diagnosis of tumours presenting in the lacrimal gland region.

\section{References}

1 Schatz H. Benign orbital neurilemmomas: sarcomatous transformation in Von Recklinghausen's disease. Arch Ophthalmol 1971; 86: 268-273.

2 Jakobiec FA, Font RL. Orbit. In: Spencer WH (ed). Ophthalmic Pathology: An Atlas and Textbook. 4th edn. WB Saunders: Philadelphia, PA, 1966, pp 2645-2664.

3 Pollock SC. Tumours of Cranial and Peripheral Nerves. In: Miller NR, Newmann NJ (eds). Walsh and Hoyt's Clinical Neuroophthalmology, Vol 2, 5th edn. William and Wilkins Co.: Baltimore, MD, 1998, pp 2297-2327.

4 Cantore G, Ciapetta P, Raco A, Lunardi P. Orbital schwannomas: report of nine cases and review of literature. Neurosurg 1986; 19: 583-588.

5 Nadkarni T, Goel A. A trigeminal neurinoma involving the lacrimal nerve: case report. Br J Neurosurg 1999; 13: 75-76.

6 Rose GE, Wright JE. Isolated peripheral nerve sheath tumors of the orbit. Eye 1991; 5: 668-673.

7 Rootman J, Goldberg C, Robertson W. Primary orbital schwannomas. Br J Ophthalmol 1982; 66: 194-204.

U Singh', J Sukhija', S Raj', BD Radotra² and A Gupta'

${ }^{1}$ Department of Ophthalmology

Post Graduate Institute of Medical Education and

Research, Chandigarh 160012, India

${ }^{2}$ Department of Pathology

Post Graduate Institute of Medical Education and

Research, Chandigarh 160012, India

Correspondence: $\mathrm{Dr} U \mathrm{~S}$ Singh

Tel: +91 $172747585 \times 224$

E-mail: grverma@mantraonline.com

The authors have no proprietary or financial interest in any article of this paper.

\section{Sir,}

Ocular tuberculosis with angle granuloma

Eye (2004) 18, 219-221. doi:10.1038/sj.eye.6700590

Tuberculosis (TB) is one of the major systemic diseases causing mortality and morbidity in developing countries. However, migration from these countries to developed countries, widespread drug abuse, predisposition of AIDS patients to mycobacterial infections, and development of multiple drug-resistant strains of the pathogen have aroused interest throughout the world. ${ }^{1,2}$

TB may affect any ocular or orbital tissue, either by an active infection or an immunologic reaction, related to delayed hypersensitivity and an aseptic reaction. ${ }^{1}$ Here 